\title{
Rancang Bangun Sistem Informasi Persediaan Spare Part Mobil Berbasis Web Menggunakan Metode ABC
}

\author{
Wahyudin $^{1}$, Ferry Kristiyanto ${ }^{2}$ \\ ${ }^{1}$ Fakultas Ekonomi \& Bisnis, Program Studi Administrasi Bisnis, Universitas Bina Sarana Informatika \\ e-mail: Wahyudin.whd@bsi.ac.id \\ ${ }^{2}$ Program studi Sistem Informasi, STMIK Nusa Mandiri Jakarta \\ e-mail: ferrykristiyanto4@gmail.com
}

\begin{abstract}
Abstrak - Persediaaan adalah unsur penting dalam sebuah perusahaan. Bukan hanya Standar operasional prosedur dalam persediaan namun pengendalian dan pengolahan sistem persediaan menjadi faktor penting dalam proses bisnis. Sistem Informasi Menggunakan Metode ABC berguna untuk membuat proses bisnis lebih efektif dan pengendalian dalam investasi persedian dapat di minimalkan. Tujuan Penelitian ini untuk membuat standard operating prosedure menjadi lebih efektif dan pengendalian atas investasi tetap terjaga pada Bengkel Tubagus Ban. Hasil dari penelitian ini menunjukan jika perlu nya membuat sebuah sistem yang terkomputerisasi agar proses bisnis pada bengkel tubagus ban ini dapat menjadi lebih baik. Hasil dari pengendalian persediaan menggunakan metode $\mathrm{ABC}$ pada Bengkel Tubagus ban ini menampilkan spare part jenis oli golongan A dengan 6 jenis spare part dan presentase permintaan sebesar 39,3\%, golongan B dengan 8 jenis spare part dengan presentase permintaan sebesar 30,8\% dan Golongan C yaitu 14 jenis spare part dengan presentase permintaan sebesar 29,9. Untuk jenis tire yaitu Golongan A dengan 5 jenis sparepart dan presentasi permintaan sebesar 41\%, Golongan B dengan 8 jenis spare part dan presentase permintaan sebesar 38,5\% dan golongan $\mathrm{C}$ yaitu 12 jenis spare part dengan presentase permintaan sebesar $20,5 \%$.
\end{abstract}

Kata Kunci: Sistem Informasi, Persediaan, Metode ABC

\begin{abstract}
Provision is an important element in a company. Not only Standard operational procedures in inventory but control and processing of inventory systems become an important factor in business processes. Information Systems Using ABC Methods is useful for making business processes more effective and control in inventory investments can be minimized. The purpose of this research is to make standard operating procedure more effective and control over investment is maintained at Tubagus Ban Workshop. The results of this study indicate if it is necessary to make a computerized system for business process on tubagus tire workshop can be better. The result of inventory control using ABC method on Tubagus Tire Workshop is showing spare part of type A oil with 6 types of spare part and demand percentage of 39,3\%, Group B with 8 type of spare part with demand percentage 30,8\% and Group $C$ is 14 types of spare parts with a percentage of demand of 29.9. For the type of tire that is Group $A$ with 5 types of spare parts and request presentation of 41\%, Group B with 8 types of spare parts and demand percentage of $38.5 \%$ and class $C$ is 12 types of spare parts with a percentage of demand of $20.5 \%$.).
\end{abstract}

Keywords: Information System, Inventory, Metode ABC

\section{PENDAHULUAN}

Di era modern saat ini kemudahaan dalam mengelola proses bisnis, baik dari segi teknologi maupun non teknologi pasti diinginkan setiap perusahaan. Tidak hanya hal di atas yang diinginkan setiap perusahaan. Standard Operating Prosedure yang baik dan perencanaan yang matang seperti, unsur-unsur penting dalam sebuah perusahaan pun diinginkan agar proses bisnis dapat bertahan. Sebagai contoh perusahaan dagang.

Menurut (Tamodia, 2013) Secara umum, perusahaan dagang dapat di definisikan sebagai organisasi yang melakukan kegiatan usaha dengan membeli barang dari pihak atau perusahaan lain kemudian menjualnya kembali kepada masyarakat. Salah satu unsur yang paling penting dalam perusahaan dagang adalah persediaan. Persediaan merupakan barang dagangan yang di beli kemudian di simpan untuk selanjutnya dijual kembali dalam operasi. Perusahaan senantiasa memberi perhatian yang besar dalam persediaan.

Menurut (Farida \& Rozini, 2016)Tanpa adanya persediaan, perusahaan akan dihadapkan pada sebuah risiko tidak dapat memenuhi keinginan para pelanggan. Perusahaan harus memiliki konsep yang baik dalam pengendalian persediaan. Dengan konsep pengendalian yang baik perusahaan dapat mengurangi kemungkinan ke tidak mampuan memenuhi permintaan pelanggan. 
Beberapa metode dapat di gunakan dalam pengendalian investasi biaya persedian dan menentukan jumlah pesanan yang ekonomis. Secara umum ada empat pendekatan metode yang dapat di gunakan, pendekatan dengan model Material Requirements Planning (MRP), Just In Time (JIT), dan model ABC analysis method.

Bengkel Tubagus Ban adalah sebuah perusahaan yang bergerak dalam bidang penjualan spare part dan jasa service mobil di kawasan Jakarta Barat, tepat nya pada Jalan.Jelambar Fajar Teluk. Gong Selatan No.1A, RT.4/RW.6, Pejagalan, Penjaringan, Kota Jakarta Utara, Jakarta. Bengkel Tubagus Ban ini tidak membuat spare part melainkan Spare part tersebut di beli dari supplier. Ketersediaan spare part sangat berpengaruh pada perencanaan proses bisnis. Dalam pengolahan data persediaan spare part masih menggunakan cara semi komputerisasi yaitu mengunakan Microsoft Excel, serta masih menggunakan cara yang kurang efektif pada Standard Operatating Prosedures (SOP) sistem persediaan. Dimana untuk proses pemesanan persediaan pada Bengkel Tubagus Ban menggunakan media telepon untuk memesan spare part tanpa ada nya bukti print out pemesanan untuk supplier. Sehingga supplier hanya mendapat bukti pemesanan secara lisan atau verbal saja, yang memungkinkan terjadinya kesalahan atas pemesanan barang yang di lakukan Bengkel Tubagus Ban.

Dalam penerimaan barang yang di pesan Bengkel Tubagus Ban ini juga masih dinilai kurang efektif, karena staff yang bersangkutan untuk menerima barang hanya menandatangani surat barang terkirim (Delivery Order) lalu menyimpan nya pada kotak penyimpanan berkas. Sehingga jika suatu saat berkas tersebut di butuhkan akan sangat sulit untuk melakukan pengecekan berkas tersebut.

Masalah lain nya pada Bengkel Tubagus Ban ini yaitu dalam pemesanan barang persediaan yang di lakukan tidak menentu. Seharus nya perusahaan yang memiliki jumlah persediaan yang sangat banyak dan berfluktuasi tentu tidak mungkin untuk memberikan prioritas yang sama pada setiap jenis persediaan. Diperlukan pengendalian yang dapat mengkategorikan persediaan sehingga perusahaan dapat memprioritaskan persediaan dengan tepat dan efisien.

Menurut (Farida \& Rozini, 2016)Pengelompokan ABC dalam pengendalian persediaan berawal dari konsep 80-20 yang dikenal sebagai hukum Pareto. Konsep 80-20 berguna untuk merencanakan persediaan bilamana klasifikasi ABC akan diterapkan untuk jenis barang yang jumlahnya banyak sekali. Persediaan akan dibagi menjadi 3 kelompok, yaitu disebut kelompok A yang mempunyai nilai penjualan $80 \%$ dari $20 \%$ jenis barang, kemudian kelompok $\mathrm{B}$ adalah yang mempunyai nilai penjualan $15 \%$ dari $30 \%$ jenis barang, dan sisanya masuk ke kelompok C.

Penulis berasumsi bahwa dengan menggunakan metode ABC jumlah pemesanan persedian yang ekonomis dapat di capai dan dapat menekan biaya dari persediaan sehingga biaya investasi persediaan yang di keluarkan lebih effisien.

\section{METODOLOGI PENELITIAN}

\section{Metode Pengumpulan Data}

Pada penelitian ini penulis menggunakan metode deskriptif, yaitu metode yang menggambarkan suatu keadaan atau permasalahan yang sedang terjadi berdasarkan fakta dan data-data yang diperoleh dan dikumpulkan pada waktu melaksanakan penelitian. Pengumpulan data dengan dengan melakukan pengamatan dan peninjauan kegiatan secara langsung di bagian admin dan kasir pada Bengkel Tubagus Ban. Sehingga memperoleh gambaran dan pedoman penyusunan sistem informasi pada Bengkel Tubagus Ban dalam kegiatan pengendalian dan pengelolaan persediaan barang. Observasi ini dilakukan pada 22 November 2017.

Pengumpulan data dengan cara melakukan komunikasi dan wawancara secara langsung dengan pihak-pihak terkait yaitu Irmawati Admin pada Bengkel Tubagus Ban yang bertugas langsung dalam proses pengolahan data persedian barang dan pemilik yaitu Bapak Juliadi Juliani tentang bagaimana Standard Operating Prosedures pada sistem persediaan Bengkel Tubagus Ban. Wawancara ini di lakukan pada tanggal 23 dan 25 November 2017

Jenis data yang digunakan dalam penelitian ini adalah data kuantitatif. Data yang digunakan adalah berupa Laporan Data persediaan Spare Part oli dan ban per September - Oktober 2017 Bengkel Tubagus Ban.

\section{Tahapan Penelitian Menggunakan Metode} ABC

Menurut (Dunia \& Wasilah, 2013) ABC (Activity Based Costing) didefinisikan sebagai suatu sistem pendekatan perhitungan biaya yang dilakukan berdasarkan aktivitas-aktivitas yang ada di perusahaan.

Menurut (Farida \& Rozini, 2016) Pengklasifikasian berdasarkan analisis ABC dilakukan dengan mengelompokan persediaan berdasarkan nilai penjualan. Tahap-tahap yang dilakukan dalam pengklasifikasian berdasarkan analisis ABC adalah :

1. Membuat daftar semua item yang diklasifikasikan dan harga beli masingmasing item

2. Menentukan jumlah penjualan rata-rata per tahun untuk setiap item tersebut.

3. Menentukan nilai pemakaian per tahun setiap item dengan cara mengalikan jumlah penjualan rata-rata per tahun dengan harga beli masing-masing item.

4. Menjumlahkan nilai penjualan tahunan semua item untuk memperoleh nilai total penjualan.

5. Menghitung presentase penjualan setiap item dari hasil bagi antara nilai penjualan per tahun setiap item dengan total nilai penjualan per tahun.

6. Mengurutkan sedemikian rupa nilai penjualan tahunan semua persediaan yang memiliki nilai 
uang paling tinggi sampai terendah agar mempermudah pembagian persediaan atas pengelompokan $\mathrm{A}, \mathrm{B}$, dan $\mathrm{C}$ sesuai dengan aturan pengklasifikasian yang dipakai, yaitu disebut kelompok A $20 \%$ jenis spare part, disebut kelompok B dari $30 \%$ jenis spare part, dan sisanya disebut kelompok C dari $50 \%$ jenis spare part.

\section{HASIL DAN PEMBAHASAN}

Sistem persediaan barang (inventory) adalah sistem penginputan barang masuk dan keluar secara komputerisasi melalui prosedur tertentu yang nanti nya dapat di olah dan di pertanggung jawab kan sesuai dengan proses bisnis. Bengkel Tubagus Ban dalam pembelian spare part selama ini tidak menggunakan sebuah metode untuk memilih spare part mana yang memerlukan perhatian khusus dalah jumlah stock nya agar nilai investasi persedian tepat dan lebih efektif. Sebagai langkah awaal untuk membuat nilai investasi persedian yang efektif maka di buat lah sebuah filing data persedian barang antara bulan September - Oktober 2017 Untuk membantu menentukan jenis spare part mana yang harus mendapat perhatian khusus. Disini dalam menentukan pengelompokan jenis spare part tersebut dengan menggunakan metode ABC. Setelah Mengetahui Pengelompokan jenis spare part mana saja yang harus memerlukan perhatian khusus dalam nilai investasi persediaan pada bengkel Tubagus Ban, dibuat sebuah Standar Operating Prosedure yang baik dengan memanfaatkan sebuah sistem persediaan yang terkomputerisasi. Sistem yang di bangun dalam penelitian ini adalah sistem yang dapat diakses hanya di dalam lingkungan bengkel Tubagus Ban saja. Dimana Sistem Persediaan Spare Part ini digunakan oleh admin, kasir dan pemilik.

Berikut Daftar Jenis spare part yang telah di kelompokan menggunakan metode ABC.

\section{A. Pengelompokan Persediaan Spare Part Menggunakan Metode ABC}

Tabel 1

Detail hasil analisis ABC pada jenis spare part oli

\begin{tabular}{ccccc}
\hline $\begin{array}{c}\text { Kelom } \\
\text { pok }\end{array}$ & $\begin{array}{c}\text { Jenis Spare } \\
\text { Part }\end{array}$ & $\begin{array}{c}\text { Barang } \\
\text { Terpaka } \\
\text { i }\end{array}$ & Total Harga & $\begin{array}{c}\text { Prosen } \\
\text { tase }\end{array}$ \\
\hline A & 6 & 97 & Rp. 17.428 .700 & $39,3 \%$ \\
B & 8 & 136 & Rp. 13.673 .400 & $30,8 \%$ \\
C & 14 & 235 & Rp. 13.285 .050 & $29,9 \%$ \\
$\begin{array}{c}\text { Jumla } \\
\text { h }\end{array}$ & 28 & 468 & Rp. 44387.150 & $100 \%$ \\
\hline
\end{tabular}

Sumber : Data Penelitian 2018

Dapat disimpulkan bahwa kelompok A dengan 6 jenis spare part oli mendapatkan Presentase permintaan sebesar $39,3 \%$, sedangkan kelompok B dengan 8 jenis spare part oli mendapatkan $30,8 \%$
Presentase permintaan, sisa nya yaitu kelompok C dengan 14 jenis spare part oli mendapakan 29,9\% permintaan.

Tabel 2

Detail hasil analisis ABC pada jenis spare part Tire

\begin{tabular}{|c|c|c|c|c|}
\hline $\begin{array}{c}\text { Kelom } \\
\text { pok }\end{array}$ & $\begin{array}{c}\text { Jenis Spare } \\
\text { Part }\end{array}$ & $\begin{array}{c}\text { Barang } \\
\text { Terpaka } \\
\mathbf{i}\end{array}$ & Total Harga & $\begin{array}{c}\text { Prosen } \\
\text { tase }\end{array}$ \\
\hline A & 5 & 60 & Rp. 58.130.000 & $39,3 \%$ \\
\hline B & 8 & 63 & Rp. 54.588.800 & $30,8 \%$ \\
\hline C & 12 & 25 & Rp. 29.018.080 & $29,9 \%$ \\
\hline $\begin{array}{c}\text { Jumla } \\
\text { h }\end{array}$ & 25 & 148 & Rp 141.736.880 & $100 \%$ \\
\hline
\end{tabular}

Sumber : Data Penelitian 2018

Dapat disimpulkan bahwa kelompok A dengan 5 jenis spare part tire mendapatkan Presentase permintaan sebesar 41,0\%, sedangkan kelompok B dengan 8 jenis spare part tire mendapatkan 38,5\% Presentase permintaan, sisa nya yaitu kelompok $\mathrm{C}$ dengan 14 jenis spare part oli mendapakan $20,5 \%$ permintaan.

\section{B. Logical Record Structure}

merupakan teknik yang digunakan untuk memodelkan kebutuhan data dari suatu organisasi, biasanya oleh System Analys dalam tahap analisis persyaratan proyek pengembangan system. Berikut adalah pemodelan yang penulis buat untuk Sistem Informasi Persediaan spare part.

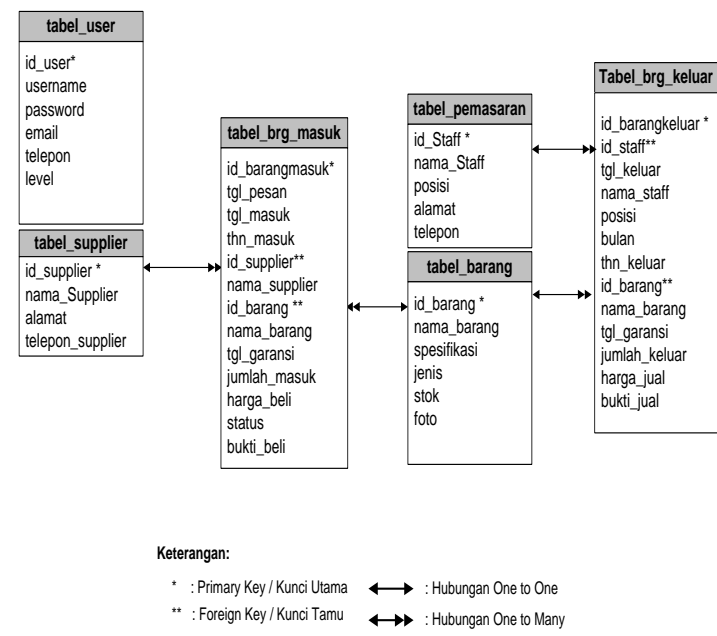

Sumber : Data Penelitian 2018

Gambar 1. LRS

Sistem Informasi Persediaan Spare Part Bengkel Tubagus Ban

C. Entity Relationship Diagram (ERD) 
Bentuk ERD (Entity Relationship Diagram) yang menggambarkan model basis data sistem yang di buat adalah sebagai berikut:

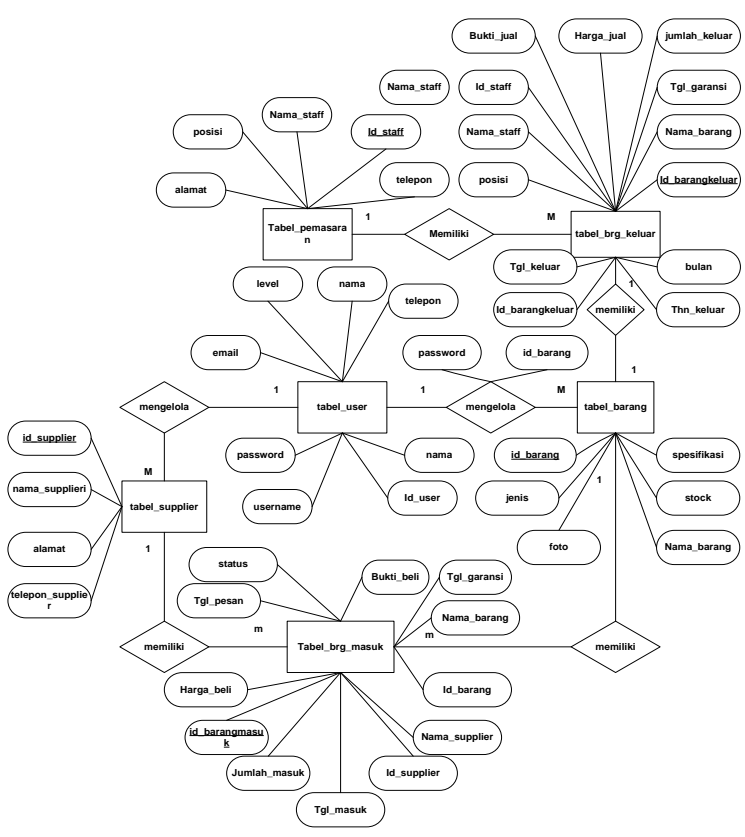

Sumber : Data Penelitian 2018

Gambar 2. ERD

Sistem Informasi Persediaan Spare Part Bengkel Tubagus Ban

\section{User Interface}

1. Halaman Utama Sistem Informasi Persediaan Spare Part Bengkel Tubagus Ban

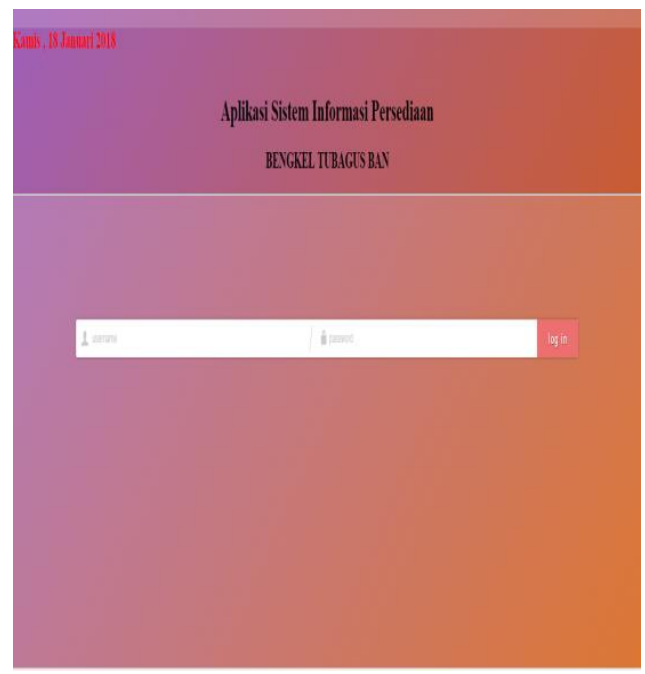

Sumber : Data Penelitian 2018

Gambar 3. Halaman Login

Sistem Informasi Persediaan Spare Part Bengkel Tubagus Ban

\section{Halaman Beranda Admin Sistem Informasi Persediaan Spare Part Bengkel Tubagus Ban}

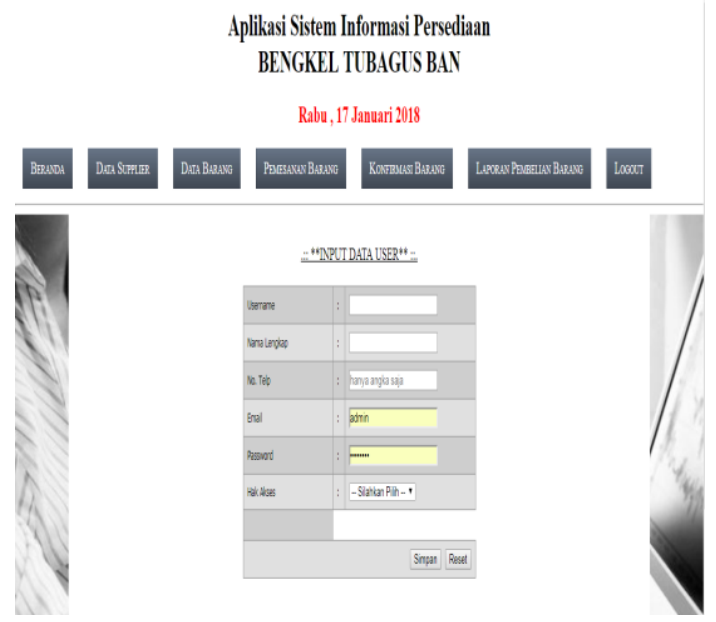

Sumber : Data Penelitian 2018

Gambar 4. Halaman Beranda Admin

Sistem Informasi Persediaan Spare Part Bengkel Tubagus Ban

\section{KESIMPULAN}

Dari hasil analisi, desain pengkodean sampai tahapan implementasi Perancangan Sistem Informasi Persediaan Spare Part Mobil Berbasis Web Dengan Menggunakan Metode ABC pada Bengkel Tubagus Ban Jakarta, penulis dapat menarik kesimpulan bahwa:

A. Dengan ada nya Sistem Informasi Persediaan Spare Part Berbasis web sangat membantu sekali pihak perusahaan dalam menjalankan proses bisnis dengan Standard Operating Prosedures (SOP) yang baik dan benar.

B. Sistem Persediaan Spare Part ini merupakan Aplikasi sistem terkomputerisasi yang di buat berbasis web dan membuat database pengolahan data secara terpusat, sehingga dapat mengolah database tersebut menjadi informasi yang di butuhkan perusahaan.

C. Sistem informasi persediaan spare part Bengkel Tubagus Ban memilik beberapa keuntungan sebagai berikut:

1. Dapat meminimalkan kesalahan yang bersifat human error.

2. Adanya peningkatan effisiensi dan efektifitas waktu proses bisnis nya.

3. Pencarian data dan pembuatan laporan akan menjadi lebih mudah.

D. Dengan adanya pengelompokan spare part pada Bengkel Tubagus Ban dapat membantu perusahaan untuk lebih memperhatikan mana yang menjadi prioritas utama pada jenis spare part yang memilik nilai investasi paling tinggi. 


\section{REFERENSI}

Dunia, F. A., \& Wasilah, A. (2013). Akuntansi Biaya. Jakarta: Salemba Empat.

Farida, I., \& Rozini, M. N. (2016). No Title. Pengendalian Persediaan Spare Part Dan Pengembangan Dengan Konsep 80-20(Analisis Abc) Pada Gudang Suku Cadang PT Astra International Tbk-Daihatsu Saes Operasional Cabang Tegal, (Jurnal Akuntansi SENIT),
163-169.

Tamodia, W. (2013). No Title. Evaluasi Penerapan Sistem Pengendalian Intern Untuk Persediaan Barang Dagangan Pada PT. Laris Manis Utama Cabang Manado, 1 no.3(Jurnal EMBA), 20-29. 